\title{
Análise morfoestrutural aplicada para avaliação de suscetibilidade à degradação ambiental por erosões hídricas lineares no interior do Estado de São Paulo
}

\author{
Morphostructural analysis applied for susceptibility assessment of environmental \\ degradation by linear hydraulic erosions in the countryside of São Paulo State
}

Márcia Sayuri Morinaga ${ }^{1}$ e Jairo Roberto Jiménez-Rueda ${ }^{1}$

'Departamento de Petrologia e Metalogenia, Instituto de Geociências e Ciências Exatas, Universidade Estadual Paulista UNESP, Avenida 24A 1.515, CEP 13506-900, Rio Claro, SP, BR (sayurimorinaga@gmail.com; jairorj@rc.unesp.br)

Recebido em 20 de agosto de 2014; aceito em 26 de janeiro de 2015

\begin{abstract}
Resumo
O Oeste do Estado de São Paulo é conhecido pela sua forte vocação agrícola e pelos problemas com erosão. As condições naturais e a dinâmica de ocupação foram propícias para o surgimento deste tipo de degradação ambiental no solo, resultando em perda de área útil, assoreamento de corpos d'água e demandas na infraestrutura. Erosões hídricas lineares, como ravinas e voçorocas, têm como fatores de formação o clima, o solo, a declividade do terreno e o uso. Para ampliar o conhecimento sobre este assunto, objetivou-se uma análise das deformações geológicas de caráter dúctil, e subordinadamente rúptil, e suas relações com as erosões hídricas lineares aceleradas da região de Marília, no Estado de São Paulo, por meio da interpretação dos elementos de drenagem e imagens de sensores remotos. De maneira geral, houve correspondência entre as áreas potencialmente suscetíveis à erosão diagnosticadas pelo mapeamento morfoestrutural associado à topografia, com o estado atual de degradação dos terrenos, resultante de um século de exploração da terra. A análise morfoestrutural em conjunto com a topografia, além de trazer a compreensão da dinâmica de circulação de água subsuperficial, pode ser aplicada para planejamento territorial.
\end{abstract}

Palavras-chave: Geologia aplicada; Degradação de solo; Planejamento ambiental; Centro-oeste paulista.

\begin{abstract}
The Westside of the State of São Paulo, in Brazil, is known by its strong agricultural vocation and erosion problems. The natural conditions and the occupation dynamic were propitious to the emergence of this kind of environmental degradation in the soil, resulting in loss of usable area, siltation of water bodies, and demands on infrastructure. Linear hydraulic erosions, such as gullies, have as forming factors the climate, soil, land slope, and usage. In order to enrich the knowledge on this subject, the present work aimed at an analysis of the ductile geologic deformations, and subordinate brittle, and its relations to the accelerated linear hydraulic erosions in the region of Marília, in the State of São Paulo, through the interpretation of the elements of drainage and remote sensing images. In general, there was correspondence between the areas potentially susceptible to erosion diagnosed by morphostructural mapping and topography, with the current state of degradation that is a result from a century of exploitation of the land. The morphostructural and topographic analyses bring the understanding of subsurface water dynamics, and can be applied to territorial planning.
\end{abstract}

Keywords: Applied geology; Soil degradation; Environmental planning; Midwest São Paulo. 


\section{INTRODUÇÃO}

A ocupação do território brasileiro remonta uma história de cinco séculos de mudanças na composição de uso e cobertura. O Estado de São Paulo é considerado de grande importância econômica, e toda a sua região Oeste é fortemente ocupada pela agricultura em função de seus solos férteis e relevo suave. No entanto, a problemática da erosão tornou-se um destaque pela recorrência e pelos prejuízos econômicos.

A erosão é o processo de desagregação e remoção do solo, tendo como agentes a água, o vento, o gelo, as ondas do mar e os movimentos de massa. A intensidade da erosão relaciona-se com o tipo de solo, da sua cobertura, da geologia, do clima e da topografia da área (Morgan, 2005). A erosão linear é formada pela concentração do fluxo de água, cujos sedimentos em suspensão promovem um forte atrito com o fundo dos pequenos canais, formando sulcos. Sucessivos processos de erosão e deposição causam turbulência no fluxo da água, o que favorece a dissecação vertical do terreno. $\mathrm{O}$ aprofundamento do canal pode alcançar centenas de metros de comprimento e denomina-se voçorocas ao apresentar paredes verticais métricas com fluxo de água no fundo, as quais são de difícil recuperação (Almeida Filho et al., 2004; Bigarella e Mazuchowski, 1985; Dietrich et al., 1993; Guerra, 1995, 2010; São Paulo, 1989).

Estudos sobre degradação ambiental devem levar em consideração uma análise dos componentes do meio físico para um entendimento amplo das dinâmicas atuantes. Dessa forma, análises das deformações geológicas permitem a compreensão da estruturação e esculturação da paisagem, pois são resultados dos processos endógenos e exógenos. Especialmente os comportamentos de estruturas dômicas e depressivas, formadas por flexuras nas rochas e materiais sobrejacentes, conferem variações locais das propriedades do relevo, permitindo inferir o potencial natural de degradação ambiental.

No caso do interior paulista, a tectônica intracratônica é caracterizada pela influência do embasamento cristalino, o qual, devido a sua rigidez, tende a gerar flexuras somente regionais. No entanto, rupturas e deslocamentos de blocos, gerados por reativação de falhas preexistentes, oferecem propriedades de deformações locais para a cobertura estratigráfica, de maneira que o grau de deformação depende da intensidade do deslocamento e da rigidez flexural dos estratos. Assim, os blocos falhados geram propriedades de altos e baixos estruturais para os materiais da cobertura (Soares et al., 1981).

As propriedades de estruturas anticlinais e sinclinais exercem um importante papel sobre a circulação de água subsuperficial, que definem o grau de intemperismo e a evolução do solo. De forma geral, os altos estruturais, independentemente do tipo de litologia, têm propriedade dispersora de água e intemperismo intenso. Já os baixos possuem uma concentradora, prevalecendo morfogênese sobre pedogênese (Jiménez-Rueda et al., 1993).

A esculturação de tais estruturas as define em diferentes formas de relevo e topografia. A soma deste fator permite uma diferenciação na intensidade da circulação de água e, consequentemente, dos processos intempéricos na cobertura. Isso permite realizar um diagnóstico de suscetibilidade da área à erosão e da potencialidade de usos, para que a análise morfoestrutural possa ser utilizada como um estudo preliminar ao planejamento territorial (Jiménez-Rueda et al., 1993).

Portanto, o presente trabalho teve como objetivo demonstrar a relação entre a frequência atual de erosão linear e as potencialidades de sua formação, indicadas pela análise morfoestrutural na região de Marília, no interior do Estado de São Paulo.

\section{Área de estudo}

A análise morfoestrutural e o levantamento das erosões lineares foram realizados na região de Marília, no Centrooeste do Estado de São Paulo, Brasil. Tal local está inserida na bacia hidrográfica dos rios Aguapeí e Peixe (Unidades de Gerenciamento de Recursos Hídricos 20 e 21, respectivamente), que foi considerada por São Paulo (1989) como a região mais afetada por erosão no estado. $\mathrm{O}$ estudo limitouse a uma área compreendida entre as longitudes $49^{\circ} 45^{\prime} \mathrm{W}$ e $50^{\circ} 15^{\prime} \mathrm{W}$ e latitudes $22^{\circ} 00^{\prime} \mathrm{S}$ e $21^{\circ} 15^{\prime} \mathrm{S}$, com aproximadamente $1.441 \mathrm{~km}^{2}$, que compreende partes dos municípios de Marília, Oriente, Pompeia, Júlio Mesquita, Álvaro de Carvalho, Vera Cruz e Garça (Figura 1).

Os registros de ocupação desta região são anteriores à década de 1910, cujas florestas estacionais semideciduais submontanas foram substituídas por cultura de café em grandes fazendas. Com a crise do café na década de 1940, houve predomínio do cultivo de algodão. $\mathrm{O}$ esgotamento do solo levou ao início do ciclo do amendoim, que alavancou a economia na região com as indústrias alimentícias na década de 1970. Atualmente, há uma diversificação de cultura no cenário agropecuário (Baldassarani e Hespanhol, 2011; IBGE, 2013; Mourão, 1994).

Os principais núcleos urbanos da região acompanham o relevo, ocupando o topo do Planalto Residual de Marília, um platô que atinge altitudes de 500 a $1.000 \mathrm{~m}$, formado por colinas de topos aplainadas na cimeira e escarpas festonadas, as quais limitam o perímetro urbano de Marília e Pompeia. Na área de análise do presente estudo, a altitude máxima alcançada pelo citado planalto é de $670 \mathrm{~m}$. Na circunvizinhança das escarpas erosivas, ocorrem colinas de topos convexos, características do Planalto Centro-Ocidental, de $500 \mathrm{~m}$ de altitude na região sob análise (IPT, 1981; Ross e Moroz, 1997).

Este planalto é sustentado pelo arenito carbonático da Formação Marília, e as colinas que circunvizinham a escarpa 
do Planalto Residual correspondem à Formação Adamantina (Figura 2). Ambas são rochas sedimentares de idades cretácicas da fase final de deposição da Bacia do Paraná, pertencentes ao Grupo Bauru. A Formação Adamantina, antecedente à Marília, é representada por um conjunto de fácies de bancos de arenitos alternados com lamitos, siltitos e arenitos lamíticos, com estruturas que caracterizam um extenso sistema fluvial meandrante, em um clima predominantemente desértico. A Formação Marília é constituída por arenitos grosseiros a conglomeráticos, de deposição de alta energia, cuja exposição prolongada permitiu a carbonatação e a formação de nódulos (Soares et al., 1980).

A Bacia Bauru, resultante da subsidência termomecânica exercida pelo derrame basáltico na Bacia do Paraná, recebeu a sequência sedimentar de rochas siliciclásticas continentais com vulcânicas associadas localmente, estendendo-se pelo
Oeste do Estado de São Paulo, Noroeste do Paraná, Leste de Mato Grosso do Sul, no Triângulo Mineiro e no Sul de Goiás. Possui seu limite definido em grande parte pela tectônica, composta pela Antéclise de Rondonópolis a Noroeste; pelo Soerguimento do Alto Paranaíba ao Nordeste; pelo alinhamento do rio Mogi-Guaçu, São Carlos-Leme e Ibitinga-Botucatu ao Leste, do Paranapanema ao Sudeste e do rio Piquiri ao Sul (Fernandes e Coimbra, 1994; Fúlfaro et al., 1982).

Segundo Riccomini (1997), três fatores tiveram interferência direta na fase geradora e modificadora da Bacia Bauru: o tectonismo na margem continental do Albiano ao Terciário, que atuou na sedimentação e no controle do nível de base regional; a deriva da placa no Neojurássico-Eocretáceo, a qual produziu esforço compressivo que resultou em deformações e deslocamentos comandados por descontinuidades preexistentes; e pela subsidência lenta e gradual e arrefecimento do

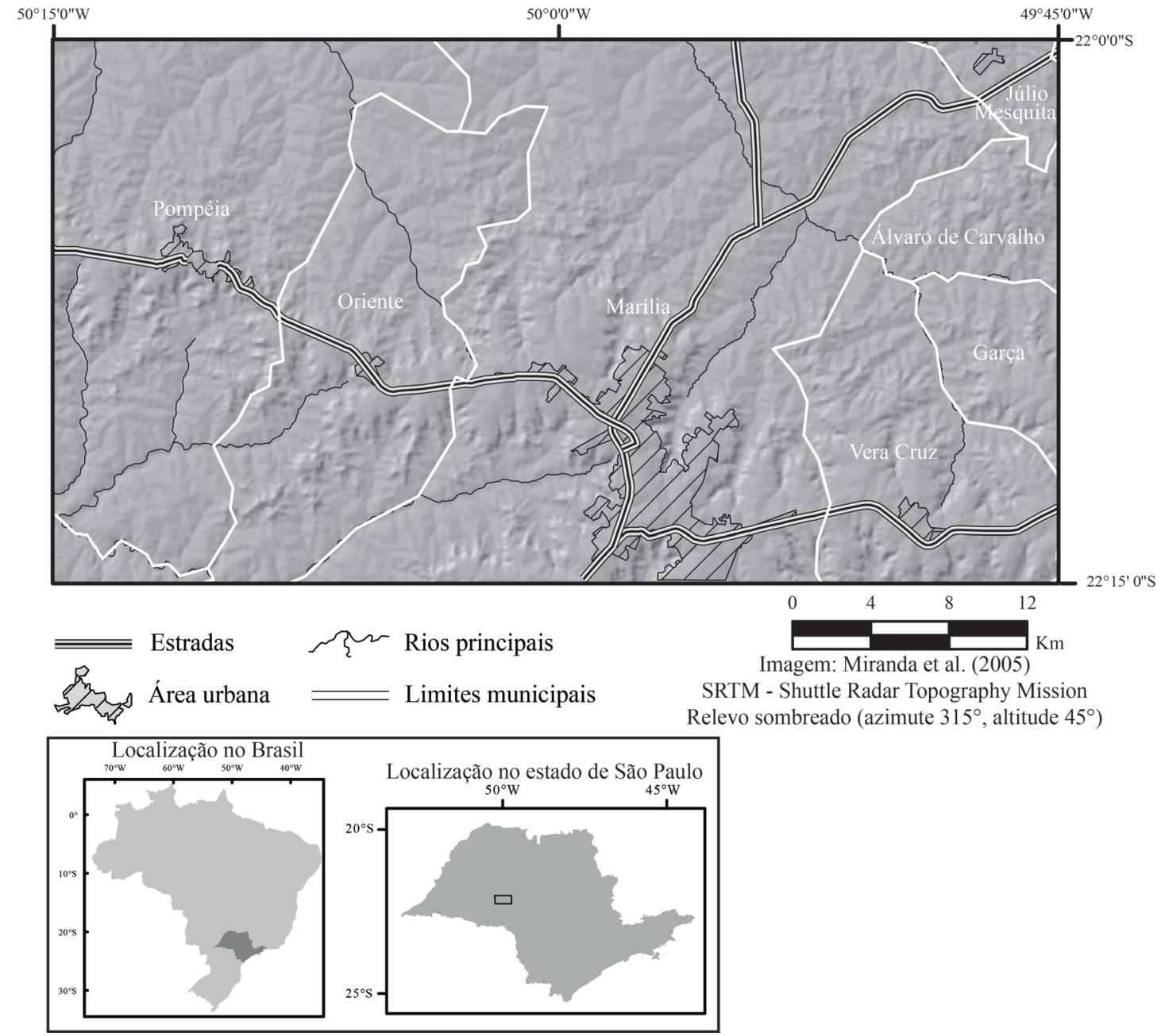

Figura 1. Localização da área de estudo. 
substrato, que permitiu a deposição da Bacia Bauru, com evidências de tectônica extensional em seu interior.

Os solos na região de análise são classificados como Argissolos Vermelho-Amarelos, podendo ocorrer em associação com Latossolo Vermelho e Neossolo Litólico, todos com horizonte A moderado. Os Argissolos são caracterizados pelo horizonte B texural, com grande concentração de argila, sendo que, na área do presente estudo, ocorreram predominantemente na região Oeste, nos municípios de Oriente e Pompeia. Foram observadas associações com Neossolos Flúvicos e Litólicos da Formação Adamantina, tanto de fácies lamítica quanto arenítica. Os Latossolos foram registrados na região central da área de estudo, entre Oriente e Marília, associados aos Argissolos e Neossolos Quartzarênicos, com textura barro argilo-arenosa. Destaca-se a predominância de cobertura arenosa em toda a área em estudo (Oliveira et al., 1999; Morinaga, 2014).

A região de Marília apresenta características que permitem aplicar a sistemática de Köppen para a classificação climática, denominando de Aw para os municípios de Júlio Mesquita, Álvaro de Carvalho, Marília, Oriente e Pompeia, e Cwa para Vera Cruz e Garça. Segundo Setzer (1966), o clima Aw enquadra-se dentro de clima úmido, como tropical de inverno seco com menos de $30 \mathrm{~mm}$ do total de chuvas no mês mais seco, temperatura média acima de $22^{\circ} \mathrm{C}$ no mês mais quente e acima de $18^{\circ} \mathrm{C}$ no mais frio. $\mathrm{O}$ clima Cwa também dentro de úmido, porém é considerado quente de inverno seco, com menos de $30 \mathrm{~mm}$ do total de chuvas no mês mais seco, temperatura média do mês mais quente acima de $22^{\circ} \mathrm{C}$ e do mais frio abaixo de $18^{\circ} \mathrm{C}$.

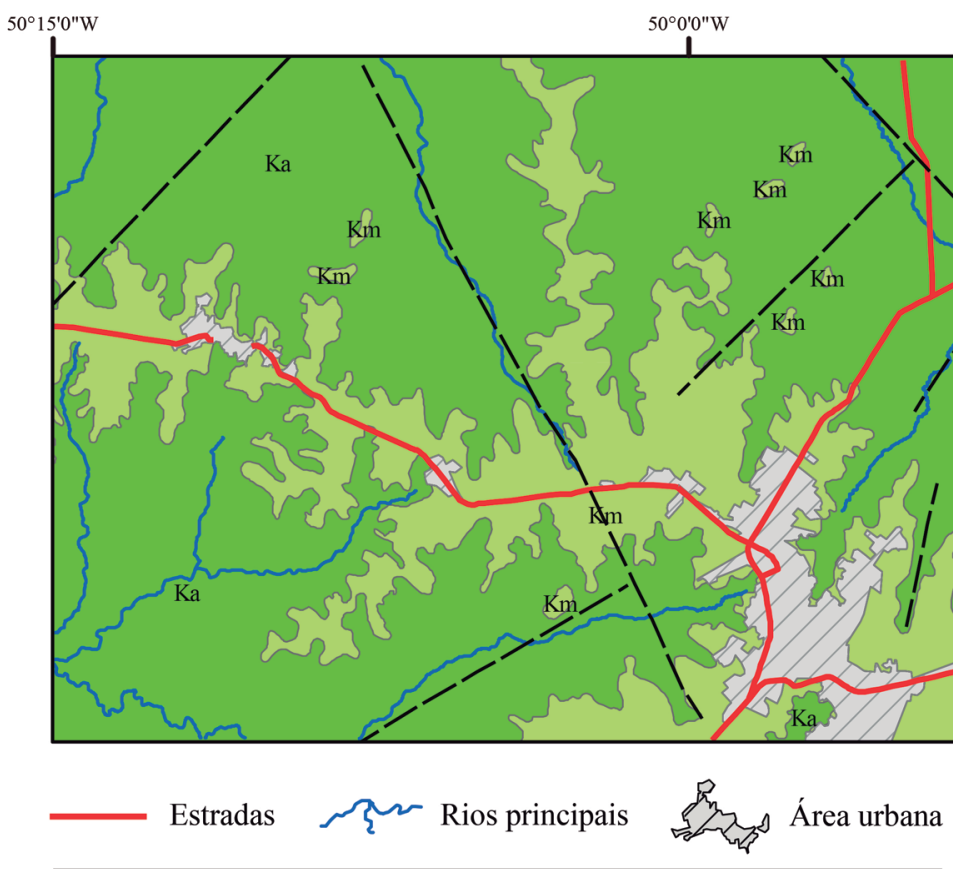

Unidades Litoestratigráficas CRETÁCEO

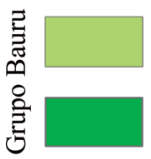

$\mathrm{Ka}$

Formação Marília - arenitos grosseiros, imaturos, maciços, abundantes nódulos calcíferos, cores creme e vermelho $\mathrm{Km}$ siltitos, cores creme e vermelho

\section{Convenção Geológica}

- - Falha inferida, lineamento fotogeológico

Figura 2. Geologia da área do presente estudo, segundo DAEE/UNESP (1982). 


\section{MATERIAIS E MÉTODOS}

O trabalho subdivide-se em duas etapas: análise morfoestrutural e frequência de erosão hídrica linear.

\section{Análise morfoestrutural}

O método de levantamento e interpretação morfoestrutural seguiu a sistematização de Soares e Fiori (1976) e Soares et al. (1981), os quais distinguem as etapas em fotoanálise, com critérios definidos para estabelecer os elementos de drenagem e relevo, sua classificação e associação; e em fotointerpretação, que são os parâmetros para a busca de um significado geológico às diferentes formas levantadas.

Dessa forma, o material-base para a fotoanálise é o traçado da drenagem, entendendo-se como essa todos os canais de escoamento de água, permanentes ou não. Tal componente da paisagem foi obtido por extração e adensamento de drenagem, por meio de cartas topográficas 1:50.000 (Folhas Marília e Pompeia) do Instituto Brasileiro de Geografia e Estatística - IBGE (1973).

As formas analisadas e as suas correspondentes interpretações, de acordo com Soares e Fiori (1976) e Soares et al. (1981), foram:

- Formas anômalas anelares e radiais de drenagem - a forma anelar de drenagem, quando controlada por estruturas dômicas ou depressões, concorda com o acamamento ou fraturamento anelar, cuja geometria arqueada é resultado da flexão das camadas. A probabilidade de correspondência de uma drenagem anelar à estrutura geológica pode ser obtida de acordo com o grau de estruturação da forma. A drenagem radial pode indicar o sentido de mergulho da camada, ou fraturamento estrutural, sendo uma propriedade para a determinação de alto ou baixo estrutural (Figura 3).

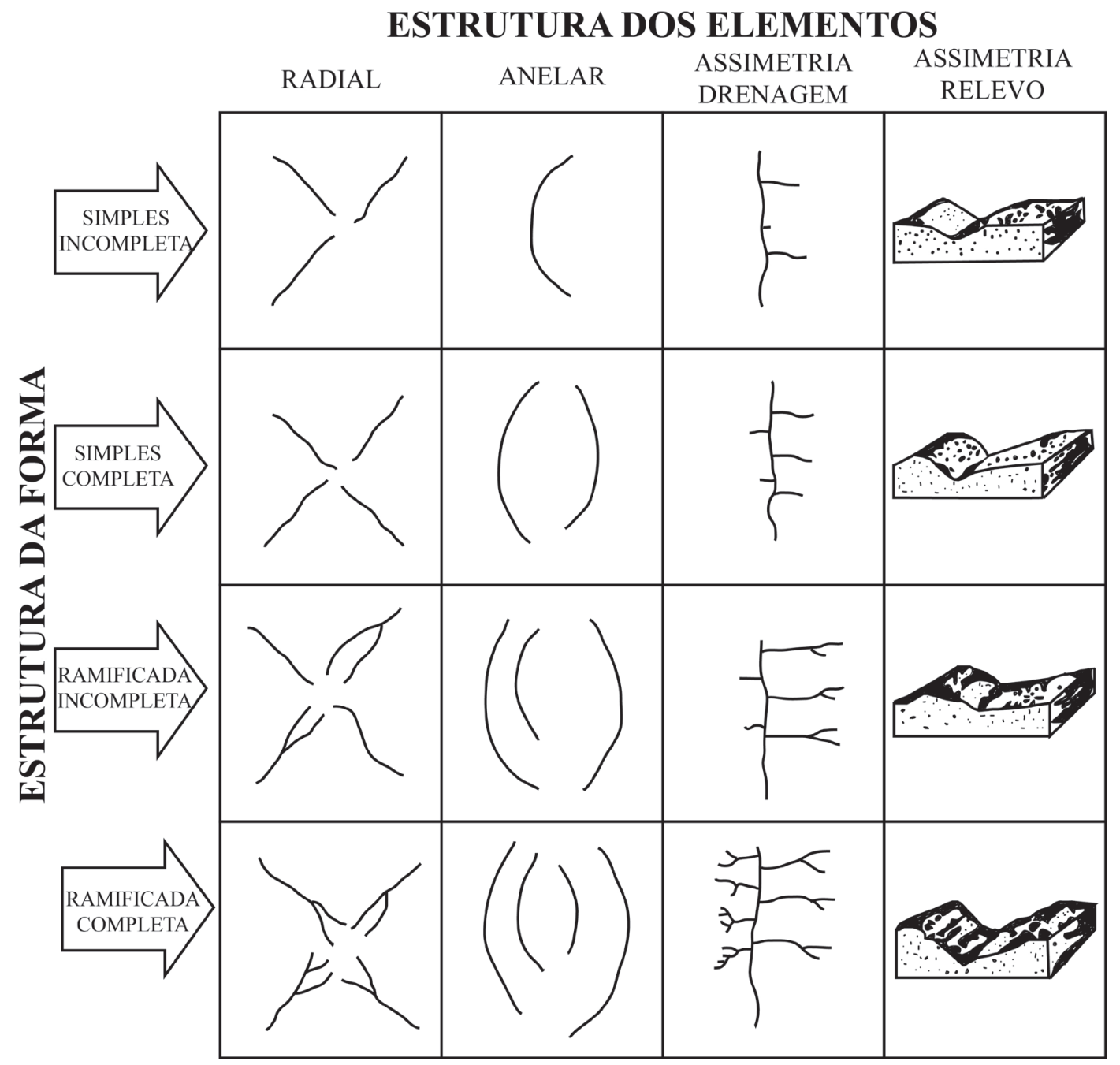

Figura 3. Esquemas do critério de interpretação morfoestrutural (Soares et al., 1981). 
- Assimetria de drenagem e relevo - a drenagem se desenvolve nos estratos inclinados, ajustando-se ao acamamento. Naqueles pouco a moderadamente inclinados, os elementos de drenagem apresentam tamanho e/ou arranjo sistematicamente diferentes de cada lado de um elemento de ordem imediatamente superior. Assim, os elementos de maior comprimento com baixa angularidade e subparalelos geralmente ocorrem no mesmo sentido das camadas, enquanto os rios de comprimento menor e com ângulos abertos formando os "candelabros", perpendicularmente ao acamamento. A análise de relevo abrange a observação dos padrões de vales, cristas e interflúvios. O sentido do mergulho das camadas coincide com o interflúvio de menor declividade (Figura 3).

- Alinhamento de drenagem - feição fortemente estruturada, retilínea ou curvilínea, de comprimento superior a $3 \mathrm{~km}$, interpretada como lineamentos estruturais, os quais, por sua vez, podem constituir falha ou reflexos do movimento de blocos. Feixes de alinhamentos de drenagem predominantemente bidirecional de maneira anômala ao seu entorno são interpretados como reflexos de falhas em profundidade, podendo ser denominado trend estrutural (Figura 4).

A escala de interpretação morfoestrutural foi fixada em 1:100.000 e reavaliada em 1:200.000. Segundo a estruturação das formas, podem ser estabelecidos os graus de confiabilidade do mapeamento. A interpretação é realizada somente com a ocorrência concomitante das três feições anômalas de drenagem descritas.

A integração das interpretações dos traços de acamamento e dos indicativos da direção do mergulho permite definir o contorno aproximado das camadas expostas, possibilitando caracterizar áreas estruturalmente positivas e negativas e descontinuidades estruturais.

As estruturas dômicas são altamente dispersivas, independentemente do tipo de litologia, e geralmente apresentam os solos mais evoluídos e estáveis. Já os baixos estruturais exercem papel concentrador, e são locais que apresentam os solos menos evoluídos e mais instáveis. Estas áreas estruturalmente anômalas têm variação em suas propriedades de

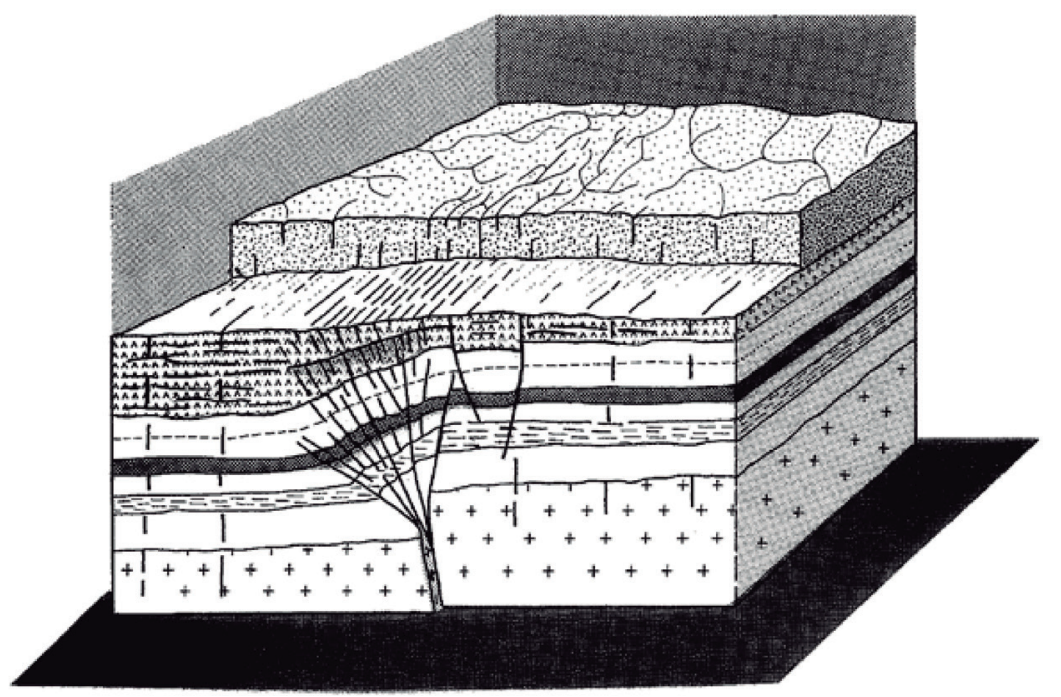

The

Cobertura arenosa posterior aos eventos tectônicos importantes

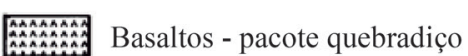

Pacote de sedimentos rúpteis e plásticos do principal evento tectônico

+++ Embasamento cristalino

III Feixe de fraturas na superfície

Figura 4. Modelo de interpretação de trend estrutural (Soares et al., 1982). 
acordo com a altitude dos elementos de relevo que compõem. A variação dos potenciais de intemperismo, circulação de água e erosão, conforme a topografia estabelecida por Jiménez-Rueda et al. (1993), está na Tabela 1.

A topografia foi obtida pelo processamento de imagem radar SRTM, de Miranda (2005), na forma de mapa hipsométrico.

\section{Isovalores de erosão hídrica linear}

As erosões hídricas lineares foram obtidas pela interpretação de fotografias aéreas ortorretificadas da Empresa Paulista de Planejamento Metropolitano S/A (EMPLASA, 2010). $\mathrm{O}$ material permitiu a visualização dos alvos em escala 1:4.000, apesar de sua acurácia posicional ter sido determinada como 1:10.000. Vales em "U" ou "V" com encostas retilíneas e marcados por solo exposto ou vegetação rasteira, em forma de erosão regressiva nas cabeceiras de drenagem do escoamento de águas pluviais ou desconectados da rede hidrográfica, foram os critérios interpretativos. A erosão foi delimitada pelo seu eixo, sendo traçados segmentos de reta no canal de escoamento de água pluvial, e foi estabelecida como unidade de erosão a cada mudança de direção. As interpretações foram confrontadas em campo (Figura 5).

A espacialização da informação de quantidade de feições erosivas foi realizada pela interpolação de frequências. Entende-se como frequência, a quantidade de feições em uma certa unidade de área. Para isso, a área de estudo foi subdividida em uma grade regular de $2 \times 2 \mathrm{~km}$, sendo realizada a contagem de feições dentro de cada unidade de área de $4 \mathrm{~km}^{2}$. Os cantos inferiores esquerdos de cada célula foram estabelecidos como a localização do ponto amostral representativos de cada célula, para a interpolação do número de erosões lineares, como podem ser observados na Figura 6. Os valores encontrados na primeira linha de células, no Norte da área de estudo, foram, então, representados na primeira linha de pontos, de forma que a espacialização dos dados ocorreu somente a partir desta. Da mesma forma, a coluna de células, no extremo Leste da área, foi representada pela última coluna de pontos, de maneira que apresentarão área sem preenchimento de informações dos isovalores. O método de espacialização dos dados adotado foi o "Vizinho Natural", pois os números estabelecidos correspondem aos valores reais dos pontos de amostragem.

\section{RESULTADOS}

O mapeamento morfoestrutural, segundo critério descrito na Figura 3, resultou em contornos com propriedades dômicas e de depressões estruturais, tendo dimensões em área de influência semelhantes. As formas variaram entre arredondadas e, predominantemente, elípticas com eixo maior variando nas direções NE, NW, NS e EW.

Um trend estrutural foi observado no eixo do rio Tibiriçá, de direção NW, coincidente com uma falha sem evidências de movimentação dos blocos levantados por DAEE/ UNESP (1982).

O mapeamento morfoestrutural e a topografia dos relevos constituintes da área de estudo podem ser observados na Figura 7.

Os baixos estruturais predominaram sobre os altos, ocorrendo nas mais variadas formas de relevo da área em estudo. Os altos estruturais, mesmo em menor ocorrência, também atingem tanto o platô (a altitudes de 630 a $650 \mathrm{~m}$, a Leste da cidade de Marília) quanto os morros residuais do Planalto (em torno de 490 a 510 m, no extremo Nordeste da área de estudo) e as colinas suaves de seu entorno (de até $470 \mathrm{~m}$ de altitude).

Considerando-se altos topográficos como a área do Planalto de Marília, e os baixos, as colinas suaves que o circundam, é possível indicar que as estruturas mais sensíveis aos processos erosivos são identificadas por 1, 11, 3 e parte do 4 . As morfoestruturas identificadas por 7, 8 e 10 podem apresentar forte suscetibilidade. Já as áreas de moderada suscetibilidade são as estruturas representadas por $9,12 \mathrm{e}$ em partes de 2,5 e 6 .

A estrutura 6, de acordo com os parâmetros de potencialidade à erosão, deve apresentar a sua metade Sul como pouco erodida e na porção Norte com erosão de forma moderada a forte.

A frequência de erosão linear em 2010, representada em isovalores, apresenta-se na Figura 8. Assim como foi mencionado, a ausência de informações nos extremos Norte e Leste da área de estudo deve-se à forma de representação dos dados adotada, em pontos rigorosamente espaçados no canto inferior esquerdo de cada célula de análise.

É possível observar uma maior ocorrência de erosão na região Nordeste da área em estudo, nas formas de relevo

Tabela 1. Propriedades das morfoestruturas conforme a variação topográfica segundo Jiménez-Rueda et al. (1993).

\begin{tabular}{lcccc}
\hline Propriedades & $\begin{array}{c}\text { Alto estrutural/Alto } \\
\text { topográfico }\end{array}$ & $\begin{array}{c}\text { Alto estrutural/Baixo } \\
\text { topográfico }\end{array}$ & $\begin{array}{c}\text { Baixo estrutural/Alto } \\
\text { topográfico }\end{array}$ & $\begin{array}{c}\text { Baixo estrutural/ } \\
\text { Baixo topográfico }\end{array}$ \\
\hline Intemperismo & Muito forte & Forte & Moderado a forte & Fraco \\
Circulação de água & Intensa & Média à alta & Baixa e direcionada & Alta e direcionada \\
Suscetibilidade à erosão & Quase nula & Moderada à forte & Muito forte à moderada & Muito forte \\
\hline
\end{tabular}




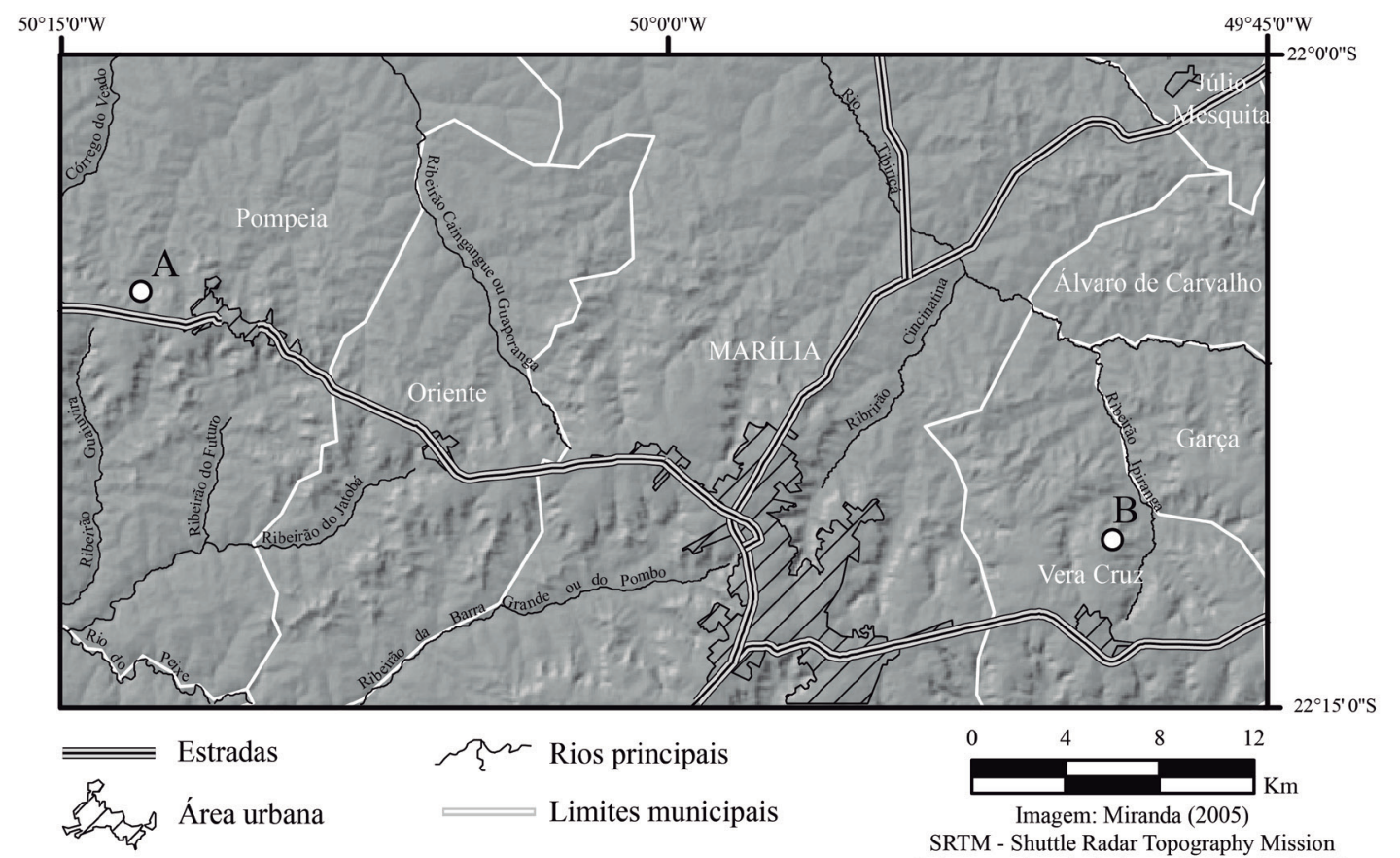

- Localização dos pontos amostrados no exemplo de erosão

Relevo sombreado (azimute $315^{\circ}$; altitude $45^{\circ}$ )
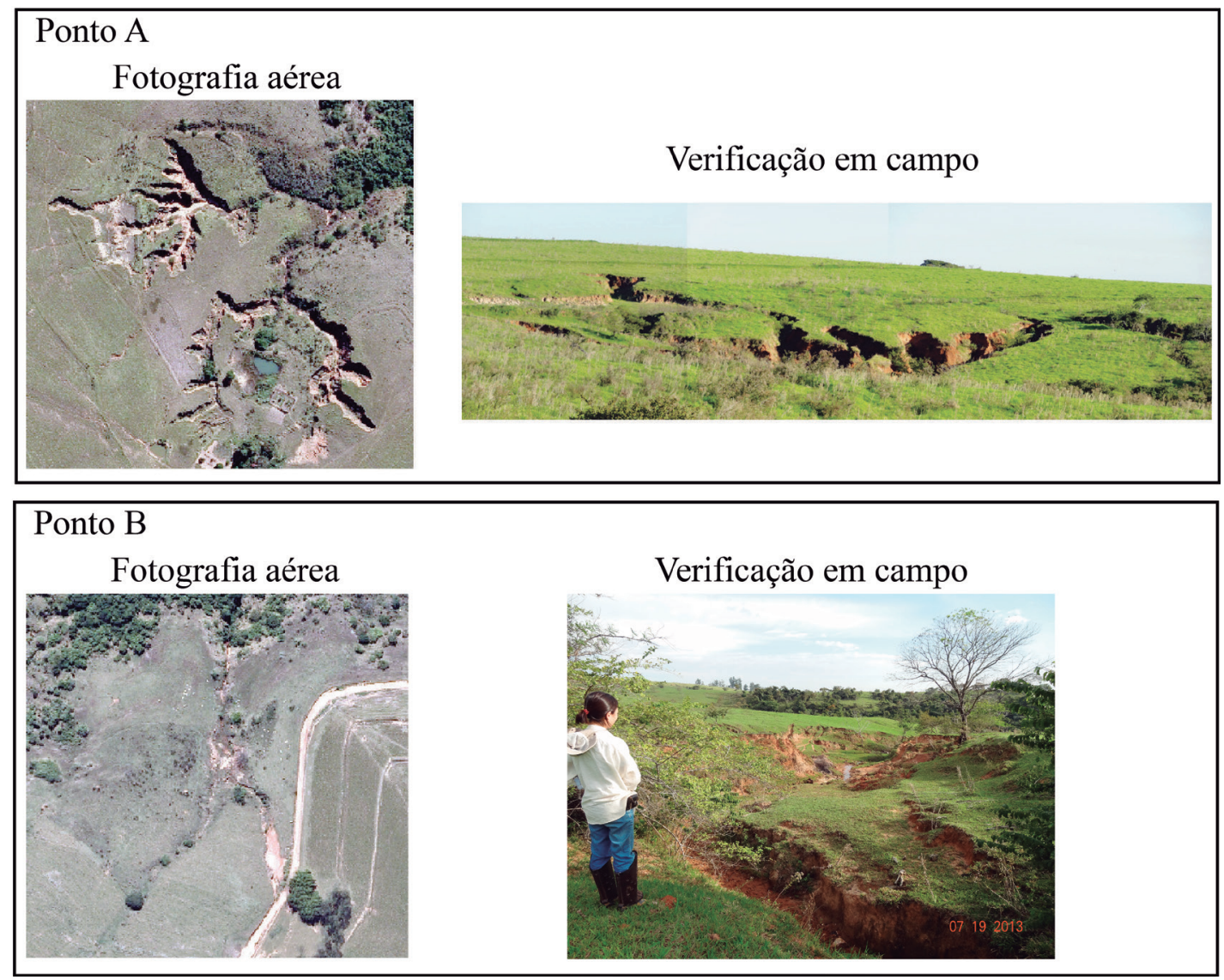

Figura 5. Exemplos de feições erosivas interpretadas em fotografia aérea e sua verificação em campo (Miranda, 2005). 


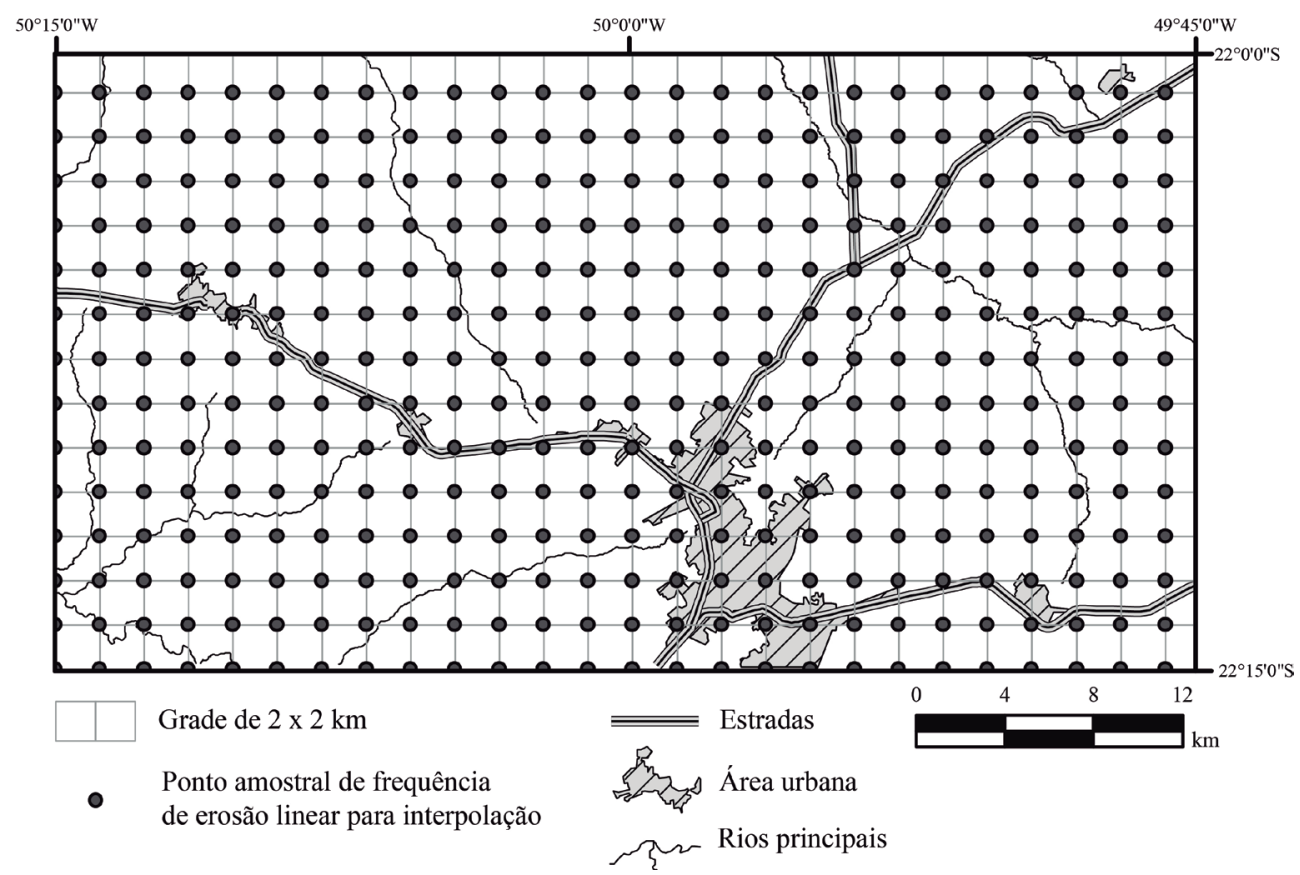

Figura 6. Método de amostragem da frequência de erosões lineares para interpolação.

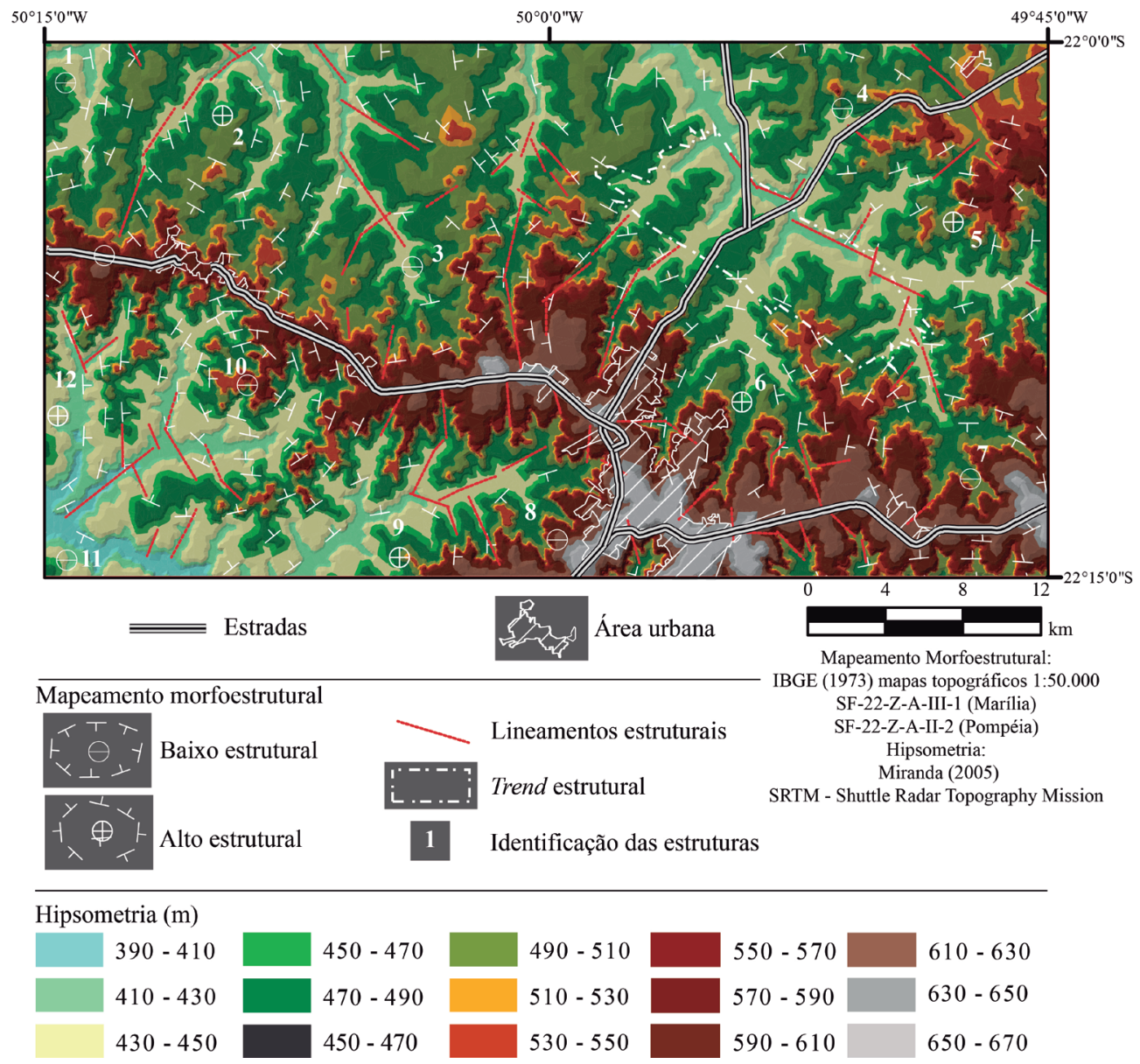

Figura 7. Mapeamento morfoestrutural e hipsometria da área de estudo (IBGE, 1973; Miranda, 2005). 


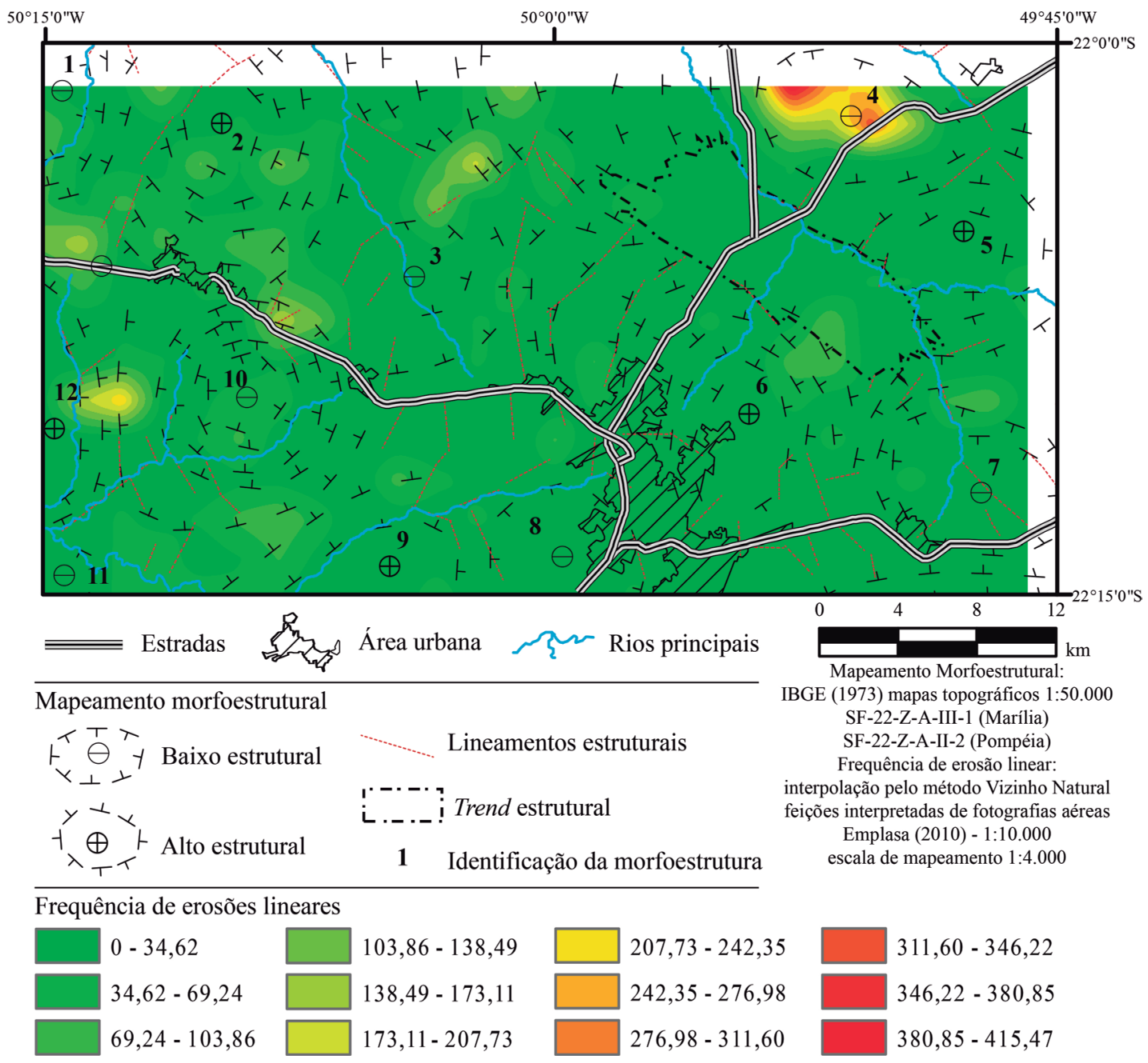

Figura 8. Mapeamento morfoestrutural e frequência de erosão hídrica linear na área de estudo (IBGE, 1973; Miranda, 2005).

residuais do Planalto nas proximidades da cidade de Júlio Mesquita, chegando a um máximo de 415 feições erosivas.

A região Oeste/Noroeste também pontua numerosas localidades com alta ocorrência de erosão linear, sendo a mais grave de aproximadamente 240 feições, a Sudoeste da cidade de Pompeia, seguida por outras duas, uma a Sudeste e outra a Oeste da mesma cidade, com máximo de 173 feições. No entorno de Pompeia, podem ser notadas regiões que possuem até 103 erosões lineares.

A porção Sudeste da área de estudo não tem a mesma recorrência de concentração de erosões lineares, sendo possível observar duas localidades com no máximo 103 feições.

Grande parte da área analisada demonstrou a mínima frequência, que variou de 0 a 34 erosões lineares.

\section{DISCUSSÃO}

A morfoestrutura 4 merece destaque por apresentar a mais alta frequência de erosão na área de estudo e uma correlação muito forte com a morfoestrutura/topografia, pois, dentro de um baixo estrutural, a variação topográfica refletiu em diferente quantidade de erosão, com intensa degradação na parte mais baixa.

Na região Oeste da área de estudo, esta correlação não se apresentou de maneira tão evidente. No entanto, a maior parte dela é moderadamente suscetível à erosão e, de certa forma, reflete no estado atual de degradação com ampla distribuição das áreas com elevada quantidade de erosões lineares. 
A não coincidência exata da linha de forma e das áreas com grande concentração de erosão pode ser explicada pelas morfoestruturas serem representações de tendência e não possibilitarem a definição do limite exato das formas.

As morfoestruturas 7 e 8 não tiveram nenhuma correlação. Apesar de sua suscetibilidade ser considerada de muito forte à moderada, não se mostrou degradada pela erosão. Isto pode ser explicado por ambas estruturas localizaremse no Planalto Residual de Marília, que é constituído por arenito com cimentação carbonática de grande resistência.

Para Silva et al. (1990), a região entre Vera Cruz e Garça, na porção Sudeste da área do presente estudo, está inserida em um alto estrutural em escala regional, cuja origem remonta à reativação da Bacia do Paraná no Turoniano-Coniaciano que resultou no levantamento da Serra do Mar.

Segundo Etchebehere et al. (2005), o rio do Peixe, que se encontra ao Sul da área de estudo, tem um comportamento tectônico ascensional, relativamente recente, apresentando atualmente vales suspensos e terraços altos. Estes movimentos de blocos modificam a condição de aplainamento, alteram o nível de base e, consequentemente, a dissecação do relevo, criando ciclos de erosão e deposição. Apesar do longo período de uso da terra e da degradação que atualmente afetam a produtividade agrícola, o dinamismo da estrutura do relevo ainda demonstra uma continuidade de tais processos, o que pode agravar ainda mais a situação de perda de área agricultável.

\section{CONCLUSÃO}

Diante do observado, pode-se afirmar que um mapeamento morfoestrutural prévio à tomada de decisões de uso e ocupação pode prevenir a degradação ambiental por erosão linear. Áreas reconhecidamente suscetíveis à formação de erosões lineares podem ser destinadas à restauração da vegetação natural, mantendo o local com baixo uso e impacto e tentando restabelecer o seu equilíbrio natural.

A região de Marília, de forma geral, é bastante sensível à formação de processos erosivos de acordo com a configuração das morfoestruturas. Somado ao seu histórico de ocupação de sua terra de um século, os resultados desta interação constam atualmente em forma de grande frequência de erosão, chegando a aproximadamente 400 feições em uma área de $4 \mathrm{~km}^{2}$.

A análise merece estudos detalhados, inclusive em outras regiões, visto que o processo de erosão, como qualquer problemática ambiental, apresenta múltiplos fatores de formação que podem ser analisados em conjunto para uma maior certeza dos resultados de previsão de degradação ambiental e, por consequência, uma maior precisão na gestão do uso de sua terra.

\section{REFERÊNCIAS}

Almeida Filho, G. S., Santoro, J., Gomes, L. A. (2004). Estudo da dinâmica evolutiva da boçoroca São Dimas no município de São Pedro, SP. I Simpósio Brasileiro de Desastres Naturais, 73-86. Florianópolis: GEDN/UFSC.

Baldassarani, J. S., Hespanhol, R. A. M. (2011). A importância do município de Marília no cenário do Centro-Oeste Paulista. V Encontro de Grupos de Pesquisa Agricultura, Desenvolvimento Rural e Transformações Socioespaciais, 1-17. Presidente Prudente: UNESP/ GEDRA.

Bigarella, J. J., Mazuchowski, J. Z. (1985). Visão integrada da problemática da erosão. III Simpósio Nacional de Controle de Erosão, 329 p. Maringá: ABGE/ADEA.

Departamento de Água e Energia Elétrica do Estado de São Paulo (DAEE)/Universidade Estadual Paulista (UNESP). (1982). Mapa geológico do estado de São Paulo - Folha Marília. Escala 1:250.000. São Paulo: DAEE/UNESP.

Dietrich, W. E., Wilson, C. J., Montgomery, D. R., McKean, J. (1993). Analysis of erosion thresholds, channel networks, and landscape morphology using digital terrain model. The Journal of Geology, 101, 259-278.

Empresa Paulista de Planejamento Metropolitano S/A (EMPLASA) (2010). Mapeia São Paulo. Escala 1:10.000. Fotografia aérea. São Paulo: EMPLASA.

Etchebeherem M. L. C., Saad, A. R., Casado, F. C. (2005). Análise morfoestrutural aplicada no vale do rio do Peixe (SP): uma contribuição ao estudo da neotectônic e da morfogênese do Planalto Ocidental Paulista. Revista Universidade de Guarulhos - Geociências, 10(6), 45-62.

Fernandes, L. A., Coimbra, A. M. (1994). O Grupo Caiuá (Ks): revisão estratigráfica e contexto deposicional. Revista Brasileira de Geociências, 24(3), 164-176.

Fúlfaro, V. J., Saad, A. R., Santos, M. V., Vianna, R. B. (1982). Compartimentação e evolução tectônica da Bacia do Paraná. Revista Brasileira de Geociências, 12(4), 590-611.

Guerra, A. J. T. (1995). Processos erosivos nas encostas. In: Guerra, A. J. T., Cunha, S. B. (Orgs.). Geomorfologia: uma atualização de bases e conceitos (149-209). Rio de Janeiro: Bertrand Brasil. 
Guerra, A. J. T. (2010). O início do processo erosivo. In: Guerra, A. J. T., Silva, A. S., Botelho, R. G. M. (Orgs.) Erosão e conservação dos solos: conceitos, temas e aplicações (1755). Rio de Janeiro: Bertrand Brasil.

Instituto Brasileiro de Geografia e Estatística (IBGE). (1973). Carta do Brasil-Escala 1:50.000. Brasília: IBGE/DAEE.

Instituto Brasileiro de Geografia e Estatística (IBGE). (2013). IBGE Cidades. Disponível em: <http://www.ibge.gov.br/ cidadesat/topwindow.htm?1>. Acesso em 28 maio 2013.

Instituto de Pesquisas Tecnológicas (IPT). (1981). Mapa geomorfológico do Estado de São Paulo. v. 2. São Paulo: IPT.

Jiménez-Rueda, J. R., Nunes, E., Mattos, J. T. (1993). Caracterização fisiográfica e morfoestrutural da Folha São José de Mipibu - RN. Geociências, 12(2), 481-491.

Miranda, E. E. (Coord.). (2005). Brasil em Relevo. Campinas: Embrapa Monitoramento por Satélite. Disponível em: $<$ http://relevobr.cnpm.embrapa.br/download/sp/sf-22-z-a. htm>. Acesso em 14 maio 2013.

Morgan R. P. C. (2005). Soil erosion and conservation. Oxford: Blackwell Publishing Ltda.

Morinaga, M. S. (2014). Análise morfotectônica e morfoestrutural no controle de erosões hídricas lineares na região de Marília (SP). Dissertação (Mestrado). Rio Claro: Instituto de Geociências e Ciências Exatas - UNESP.

Mourão, P. F. C. (1994). A industrialização do Oeste Paulista: o caso de Marília. Dissertação (Mestrado). Presidente Prudente: Faculdade de Ciência e Tecnologia - UNESP.

Oliveira, J. B., Camargo, M. N., Rossi, M., Calderano Filho, B. (1999). Mapa pedológico do Estado de São PauloLegenda expandida. Campinas: Embrapa/IAC.

Riccomini, C. (1997). Arcabouço estrutural e aspectos do tectonismo gerador e deformador da Bacia Bauru no
Estado de São Paulo. Revista Brasileira de Geociências, 27(2), 153-162.

Ross, J. L. S., Moroz, I. C. (1997). Mapa geomorfológico do Estado de São Paulo. v. 1. São Paulo: FFLCH-USP/ IPT/FAPESP.

São Paulo. Secretaria de Energia e Saneamento. Departamento de Águas e Energia Elétrica. (1989). Controle de erosão: bases conceituais e técnicas; diretrizes para o planejamento urbano e regional; orientações para o controle de boçorocas urbanas. São Paulo: DAEE/IPT.

Setzer, J. (1966). Atlas climático e ecológico do Estado de São Paulo. São Paulo: Comissão Interestadual da Bacia Paraná-Uruguai.

Silva, R. B., Etchebehere, M. L. C., Saad, A. R., Zaine, J. E., Ramos, R. G. N. (1990). O alto estrutural de Vera CruzGarça, estado de São Paulo. Geociências, (n. esp.), 279-298.

Soares, P. C, Barcellos, P. E., Csordas, S. M., Mattos, J. T., Ballieiro, M. G., Meneses, P. R. (1982). Lineamentos em imagens de Landsat e Radar e suas implicações no conhecimento tectônico da Bacia do Paraná. II Simpósio Brasileiro de Sensoriamento Remoto, 143-156. São José dos Campos: INPE.

Soares, P. C., Fiori, A. P. (1976). Lógica e sistemática na análise e interpretação de fotografias aéreas em geologia. Notícias Geomorfológicas, 16(32), 71-104.

Soares, P. C., Landim, P. M. B., Fúlfaro, V. J., Sobreiro Neto, A. F. (1980). Ensaio de caracterização estratigráfica do Cretáceo no Estado de São Paulo: Grupo Bauru. Revista Brasileira de Geociências, 10, 177-185.

Soares P. C., Mattos J. T., Balieiro M. G., Barcellos P. E., Meneses, P. R., Guerra S. M. S, Csordas S. M. (1981). Análise morfoestrutural regional com imagens de Radar e Landsat na Bacia do Paraná. III Simpósio Regional de Geologia, 201-216. Curitiba: SBG. 